\title{
Criminal Profiling Then and Now: Prospect and Challenges in Malaysia
}

\author{
Maisarah Binti Mustaffa ${ }^{1}$ \\ Muhamad Helmi Md Said ${ }^{1^{*}}$ \\ Muhammad Amrullah Bin Drs Nasrul ${ }^{2}$ \\ Muhamad Sayuti Bin Hassan ${ }^{1}$ \\ Ramalinggam Rajamanickam ${ }^{1}$ \\ Nur Khalidah Dahlan' \\ ${ }^{1}$ Faculty of Law, Universiti Kebangsaan Malaysia (UKM), \\ 436oo, Bandar Baru Bangi, Selangor, Malaysia \\ ${ }^{2}$ International Islamic University of Malaysia, \\ Jalan Gombak, 5310o, Selangor, Malaysia \\ *Corresponding Author
}

DOI: https://doi.org/10.36941/ajis-2022-0oo7

\section{Abstract}

The purpose of this article was to ascertain the concept of criminal profiling by taking into consideration the evolution of its definition, function, methodology and also the background of profiling officers from the beginning up to the present time. Using the critical and literature review approach, references from journals, books, statutes and international cases were analyzed to pinpoint the most recent developments to the criminal profiling method. While researches and literature reviews regarding criminal profiling were undoubtedly significant overseas, it was not the same case back in our homeland. Discussions were few and even then, not entirely focusing nor mentioning the procedures and practice of criminal profiling during investigation. It was also found that there seem to yet exist a clarity in regards to the definition and methodology of criminal profiling nor the background of profiler involved despite it being carried out during investigative process for a long period of time. This article also highlighted the challenges discovered in the practice of criminal profiling such as the vagueness of its method in our law, the existence of race-based profiling practice and the credibility of criminal profiling as an expert evidence in courts which was debatable due to the absence of any yardstick to determine the capability of a profiler.

Keywords: criminal profile - psychological profiling - Criminal Procedure Code - Crime Investigation

\section{Introduction}

It wasn't until the success and soaring popularity of cable series especially CBS Network's Criminal Minds that criminal profiling seemed to be gaining attention from the public. Despite having existed even way back during the year 1888 which happened to be Jack the Reaper's era, it was not formally 
recognized until around the 70's. (Asha Bolton, 2019) In 1972, an authority of the United States - the Federal Bureau of Investigation (FBI) started using a method at the time known as psychological profile which assisted in speeding up the investigation process involving unidentifiable perpetrators. The first article on criminal profiling was published by Colin Campbell in 1976 whereby researchers were asked to prove that a profiler's ability to predict the nature and characteristics of a criminal is better than that of a barkeeper. Since it was the earliest introduction to the criminal profiling method, the concept was regarded as something which was not intricate. Due to this, the background, methods, terminology as well as on site discoveries were also not defined clearly to the point that criminal profiling ended up being regarded as equivalent to how a barkeep analyzed their customers.

In Malaysia, the application of criminal profiling was indicated in Part IV, Chapter 13 and Part VIII, Chapter 33 of the Criminal Procedure Code, the latter being in regards to information to police and their powers to investigate. The provisions specifically involved were sections 109 and 329. Section 109 provided that only officers or officers in charge of stations that ranked as a Sergeant and above were qualified to conduct investigation for a sizeable case, and additionally these officers were not to be questioned at any stage of the proceeding. The duty of police officer to investigate deaths due to unidentified causes meanwhile was laid down in section 329 (Section 329 (1)(a) Criminal Procedure Code).

The application of criminal profiling method by using evidence of crime scene and remnants of the crime approach was clearly indicated in section 329(2). District Police Officer or police officers that ranked Sergeant and above had to conduct investigations based on the crime scenes and matters related to the death as well as submitting an initial finding of the crime's modus operandi. The 'investigation' provided in this context however was too general and abridged, also concentrating more onto physical evidence whereas evidence from the psychological aspect ought to be given priority as well. (Nicolae Titulescu, 2020)

Fifty years have passed by since criminal profiling marked its presence in legislation and alongside those years, hundreds of papers, researches, books, reports and so on were published. According to David Farrington in his article, "What have we learned from offender profiling? A systematic review and meta-analysis of 40 years of research", there were variations on what exactly is criminal profiling, who are qualified to conduct it, the methodologies and approaches used, discoveries reached as well as where and how the result came into conclusion. He was also of the opinion that there were minimal studies and researches found in regards to the latest update and methods used during criminal profiling on crime site. (Fox \& Farrington, 2018)

Other than that, the fact that there was no necessity for specific qualification or training to be a profiler also meant that there was no minimum standard or yardstick to measure their efficiency. The lack of practical standards resulted in the inability to impose disciplinary action or any punishment on irresponsible or incompetent profilers. The absence of a "peer-reviewed system" practice as well as unity in regards to profile making process required and methodologies used also contributed to aggravating effects such as wrongful detain and worst the likelihood of misconvictions. (Encyclopedia.com., 2019)

Therefore, in order to create an appropriate mechanism to be used in criminal profiling, this author sought to identify loopholes that would then lead towards discovering the challenges in practicing this method and further onwards, devise suggestions for improvements. For the purpose, the article has been compartmentalized into five parts that would discuss on the definition of criminal profiling, its function, the methodologies used, the background of profiling officers and the challenges of practicing criminal profiling in Malaysia. Each part would be dissected critically and comprehensively.

\section{Definition of Criminal Profiling}

A criminal profile can be constructed through a problem-solving approach from the perspectives of various branches of knowledge. It was due to this fact that the term criminal profiling can't be used in 
an integrated manner until now. Among other terms apparently being used instead were "psychological profiling", "criminal investigative analysis", "crime scene analysis", "behavioral profiling", "personality profiling", "case linkage analysis" and "behavioral consistency analysis". (Fox \& Farrington, 2018) The author chose the term criminal profiling which coincided the term used within the legal context in Malaysia. There were three branches of knowledge which happened to be the main contributors to the development of criminal profiling, namely the knowledge of psychiatry, forensics and criminology. (Lauren M. Barrow. ed. et., 2014) Hence, several definitions from each of these branches of science had to be researched and analyzed.

John E. Douglas and Alan E. Burgess defined criminal profiling as an investigation process conducted through the analysis of crime committed by a person to identify the person's key personalities as well as behavioral characteristics (John E. Douglas and Alan E. Burgess, 1998). Douglas and Burgess were special officers who managed and constructed the Behavioral Investigation Unit at the FBI Academy, also were the earliest to call attention to criminal profiling globally. This definition used the theories of offender's psychology and crime scene approach. Despite both of the researchers being enforcement officers at the time, they chose a psychiatric approach in constructing a criminal profile and became among the earliest to design a criminal profiling process. Thus, at the beginning of the development era for criminal profiling literatures, the definition by the two gentlemen was widely accepted and used by other researchers and law enforcements. However, the validity of the profiles generated have been questioned by some researchers then, whom argued that the branch of knowledge used was quite unsuitable for producing criminal profiles that can be used by law enforcements. In fact, several studies were successful in proving that the theories used by the FBI were less accurate and ought to be revised.

Geberth meanwhile in his book entitled, "Practical homicide investigation: Tactics, procedures and forensic techniques", stated that criminal profiling was a forensic technique aiming to provide specific information to investigating agencies by focusing on individuals with personality traits that were parallel to that of other perpetrators' whom committed the same crime. (Geberth, V.J, 1983) Geberth was of the opinion that a crime profile can only be obtained through scientific approaches i.e., using forensic knowledge and statistics or data by referencing to the data on traits and personality of other offenders committing similar crimes. This definition however was seen as not taking into account the psychological factors of the offender and lacked the tendency to use a theoretical approach.

Concurrently according to European police forces, criminal profiling was an attempt to produce a description of the perpetrator based on the results of an analysis of the information of the crime scene and characteristics related to the perpetrator's background. (Stevens, J.A., 1995) This definition was subsequently accepted and adopted by the Association of Chief Police Officers Behavioral Science Investigative Support Subcommittee in the United Kingdom. The definition did not see criminal profiling as a specific method but more of a preferred method in solving a crime and in most cases, it was rather incapable of telling the police who the real perpetrators are. It can in fact only suggest some of the personality and demographic characteristics that a perpetrator would likely possess. For this reason, it was inappropriate for the police to completely exclude anyone that did not possess said characteristics which have been proposed just because a criminal profile happened to be only one of the ways of identifying actual criminals.

According to Richard N. Kocsis in a book entitled, "Criminal Profiling: Principles and Practice", criminal profiling represented the process of analyzing and interpreting the behavior or action that was clearly seen in a crime. This analysis formed a prediction of the characteristics which were likely possessed by the perpetrator. Criminal profiling differed from psychological profiling since it did not concern examining incoming patients. Rather, it was an examination of the crime to interpret prominent behaviors during the time it occurred and from the analysis, the investigator would be able to produce an image of the offender (Richard N. Kocsis, 2006).

This definition seemingly was more general and broader than the previous two definitions. Kocsis took every aspect relating to crime when shaping up a criminal profile. This meant that his 
definition was more open in terms of approaches and methods that can be used by profilers when conducting investigations in order to achieve the one main goal that was to build a criminal profile of the perpetrator involved.

From a criminology perspective, criminal profiling pinpointed how exactly a crime could have happened. It did not focus on the perpetrator's character building but more on the construction of the event's chronology. Meanwhile from the psychiatric branch, criminal profiles were constructed for the purpose to find out the mental condition and the demography of the perpetrator as well as the reasons behind why such crimes have been committed. It highlighted more on the background and backstory of the perpetrator instead of focusing on how a crime actually been carried out. As for the forensics point of view, a criminal profile was build based on the remnants of evidence at a crime scene and concerning more on the methods as well as the effect of said crime.

Ultimately, criminal profiling was one of the methods that could be used by authorities to identify the dominant characteristics of a perpetrator in a particular case by taking into account the characteristics, demographics, modus operandi and evidence in similar cases which have been reported, investigated or tried in Court. This method can only be produced based on previous case studies and scientific knowledges such as criminal psychology, forensics, geography and statistics. These elements were important in escalating the percentage of accuracy for any profiles produced. However, efforts to distinguish an integrated definition of a criminal profiling was still quite difficult to be implemented due to the fact that the three branches of knowledge which were also the backbone to generating crime profiles do not have the same purposes respectively.

\section{The Functions of Criminal Profiling}

In the words of Douglas and Burgess (1986), criminal profiling served as an investigative method used by law enforcements especially the police, psychologists, academics and consultants in order to identify key personalities, behaviors and demographic characteristics of perpetrators through analysis of crime scene behaviors. To them, the profiling methods used by law enforcements as well as medical and clinical specialists were similar to each other. The term 'criminal profiling' hence have also been applied to every profiling methods used by various fields involved.

Whereas, Holmes and Holmes (1996) who preferred using the term psychological profiling instead have stated that it served to provide the criminal justice system some information regarding the social and psychological assessment of offenders, the psychological assessment of related property found with the suspected offenders and also on the consultation with law enforcement regarding the strategies used during interrogation with offenders. (Holmes \& Holmes; 1996) Holmes were more inclined to criminal profiling being one of the scientific methods that can help law enforcement confront and manage investigations against offenders. Peter B. Ainsworth meanwhile in his article entitled, "Offender Profiling and Crime Analysis", further expanded the function of the criminal profiling by stating that it was an effort to identify the characteristics, modus operandi and motives of criminals. He also stressed on that criminal profiling was an important and rational process to implement, specifically in the investigation of serial criminal cases as well as cases where the perpetrators were difficult to identify (Peter, 2001).

Richard N. Kocsis in addition stated that the general purpose of a criminal profile was to provide information to assist criminal investigations that typically involve serial or sexual violence. A criminal profile was a tool that allowed an investigation to focus on its sources and guidelines. In this case and under any circumstances, criminal profiling should not be viewed and used as a substitute for the conventional procedures normally performed in a criminal investigation. According to him, the application of a more conventional criminal profile can be used in several ways namely as a guide to identify the type and characteristics of suspects in a crime which was still under investigation; for police patrol operations which were potentially able to reduce further violations and offenses; for surveillance operations and lastly for search and seizure operations of properties. (Richard, 2006)

Koscis also observed the function of criminal profile with a broader view in which it should not 
only be focusing more on violent, sexual and serial crime offenses alone. Undeniably, it was not necessary for criminal profiling process to be applied onto all offenses yet it still could be implemented more conventionally nonetheless.

In contrast, Marco Strano however was of the opinion that crime profiles can be used in research fields such as neural networking. He started the research on using neural networks and collected data to create a computerized database based on criminal profiles that have been generated previously so that criminal and psychological profiling would be able to make use of said database in the future. The research was in fact still ongoing to further increase the knowledge on how it could help individuals be it from the law enforcements or other parties involved in the criminal justice system (Marco Strano, 2004).

Therefore, it could be summed that criminal profiling best perceived as a tool that was able to assist the authorities in speeding up and simplifying the prosecution process against the offenders, at the same time also providing assurance of justice for both the victims as well as the accused. This method has been shown to reduce the burden and percentage of pending cases in investigation. It can also be a strong piece of evidence in court if the process of building a criminal profile was monitored and filtered first through a clear set of guidelines. A reliable and unquestionable criminal profile would reduce the probability of false charges as well as convictions against suspects.

\section{Methodologies of Criminal Profiling}

Criminal profiling was all in all an effort based on expertise, logic, institutions, extensive, knowledge such as scientific philosophies, medical, forensics, criminological techniques, sociology, and so on (Nicolae Titulescu, 2020). It was therefore undeniable that various approaches have been successfully identified and used by researchers in their efforts to find the best method in producing a definitive criminal profile. There have been some methods that were abstract, general, even some that were both concrete and specific. A number of them also relied on experiences, offender group statistics and specific analysis of particular cases which focusing on behavioral evidence (Brent E. T., et al., 2012).

According to Douglas and Burgess (1968), there were seven common measures used by the FBI in conducting criminal analysis; 1 ) assessment of the criminal act itself; 2) comprehensive assessment of the crime scene; 3) comprehensive analysis of the crime victim(s);4) assessment of the initial police report; 5) assessment of the autopsy protocols performed by the medical examiner; 6) profile development using the main or significant characteristics of the criminal; and 7) proposed investigative proposals based on the construction of the crime profile. The process used was quite similar to the process used by physicians to identify diseases and formulate treatment plans for patients. This clearly shown that the criminal profiling method used by the FBI was more of a theoretical approach, by making the method of analysis by physicians as a guideline (Douglas and Burgess 1986).

The methodology received criticism by some researchers. Among them was Lea Winerman in her article, "Criminal profiling: the reality behind the myth," saying that psychologists have studied the theories used by the FBI and discovered errors in the methodological aspect. The errors were due to the lack of literature reviews done on the concept and theory of a criminal profiling itself before the FBI's profiling method was devised. Thus, some psychologists developed their own research in the field of criminal profiling and in turn have been led to discovery of new developments in terms of approaches, concepts and classification systems (Lea Winerman, 2004).

In the meantime, John E. Douglas, Robert K. Ressler, Ann W. Burgess, Carol R. Hartman through their article, "Criminal Profiling from Crime Scene Analysis", stated that basically there were two different criminal profiling techniques used to design a homicide criminal profile namely psychological profiling and criminal profiling (Douglas, \& et al., 1986). This article focused on profiling for murder crimes. Psychological profiling was the study of a criminal's actions to produce an assumption of the person's characteristics. The process of generating a criminal profile through 
this technique was similarly used by psychiatrists. Meanwhile, criminal profiling was to collect and analyze information obtained from the crime scene to reveal the type of suspect committing the crime and later a hypothesis on the category of suspects can be generated by combining crime scene analysis with various personalities of previous criminals who committed similar crimes. There were five stages of generating a criminal profile via this technique.

Various approaches have been used by researchers and law enforcement experts in producing a criminal profile. Among them were the typographic approach or classification approach, theoretical approach, clinical approach and scientifically statistical approach (Alison \& el al, 2010). Usually the approach were also categorized according to three schools of thoughts namely the criminal investigation approach, the clinical practitioner approach and the scientific approach. A study and critique conducted by Shannon Lynn Vettor on the three schools of thoughts found that the approach to criminal investigation was more dependent on the experience and institution of a profiler as well as the number of research and studies that have been successfully published (Shannon, 2011). As for the clinical practitioner approach, it was more dependent on clinical evaluations, trainings, knowledge and experiences possessed by a practitioner. They made use the inference of a motive in a crime as the key to understanding the offender. The scientific statistical approach meanwhile only focused on existing data to obtain a conclusion about the characteristics and behavior of offenders.

Next, among other studies that have been successfully identified by the author was a thesis by Norbert Ebisike entitled, "The Use of Offender Profiling Evidence in Criminal Cases", which opined that there exist four profiling approaches namely; the "diagnostic evaluation approach", "the criminal investigative analysis", "the investigative psychology" and "the behavioral evidence analysis" (Norbert, 2007). In the meantime, Nicolae Titulescu in an article "Criminal Profiling in Crime Investigation", highlighted on few profiling approaches such as the crime scene approach, statistical approach, theoretical approach, psychological investigation approach and behavioral approach (Nicolae, 2020).

Due to the difficulties that arose from procuring a uniformed methodology for crime profiling, Charles Frost through his article, "Criminal Profiling: From Art to Science", have proposed for the best approach in order to overcome the differences through each and every approaches of profiling ever existed. And that was through the "Investigative Process Management", a systematic approach on how an investigation should be conducted. By applying this approach, questions that need to be asked during an investigation have to be framed in a way to obtain an information that was unlikely to be obtained through a scene investigation and so on. Hence, an "ampliative methodology inquiry"; to know outside of existing evidence, have got to be trained into and applied. Investigators were to do their best to solve questions beyond their skills and knowledge. A mechanism needed to be developed to ensure that the questions posed are not of a purely conjectural nature but are made with due consideration (Grover Maurice Godwin. ed., $\mathrm{tt}$ ).

Undeniably, differences in the methodology used in generating a criminal profile could change the percentage of accuracy and admissibility of the profile to be used as the basis for an arrest as well as conviction of a suspect. It was quite difficult to find a single midpoint in determining the best methodology to do so. Apart from being based on relevant scientific knowledge and previous case studies, the demographic factor of the community should also be taken into account. Most of the studies on the methodology of crime profiling were based on the suitability of the western society demographic.

Ergo, the author believed that the method of constructing a crime profile in Malaysia could be done by taking into account the customs and culture of our community as one of the main sources. This was due to the fact that the dominant characteristics of the perpetrators were closely related to the demographics and practices of the local community in which the crime was committed. Therefore, several survey studies which focused on generating a crime profile based on the demographics of Asian community need to be amplified so that appropriate methodologies can be then applied as well in Malaysia. 


\section{The Backgrounds of Criminal Profiling Officers}

Based on previous studies, there have been varying percentages regarding the accuracy rate of criminal profile generated through the profiling process. However, it can help investigating officers to improve their profiling techniques especially in cases where the motive for doing so was unknown. The profile would also be able to help investigators solved violent crimes such as those involving hostages, violence threats via letters, rape, arson crimes (arsonist) and sexual murders. The key factors for a person to qualify as a law enforcement officer were investigative experience and educational background. Profilers especially needed to have a strong and encouraging investigative background by displaying achievements through significant number of records for participating, overseeing and managing major investigation cases (Douglas \&. Burgess, 1998).

Pinizzotto and several other researchers have conducted a study to compare the criminal profile generated by investigators with the profiles generated by those without a profiling background which then have been made into an article entitled "Criminal personality profiling: An outcome and process study". Studies were conducted on murder cases, fire cases and sexual assault cases which have been based on materials from actual police investigations. The respondents were four FBI profilers who were still in and have been in service; six investigating police officers with profiling trainings; six psychologists with no profiling experiences; and six university graduates also without profiling trainings.

For murder and arson cases, the findings of the study found no significant differences in the criminal profiles produced by all respondents and they have also in fact managed to produce a percentage of accuracy which have exceeded the minimum level expected by the researchers. As for sexual assault cases, the ten experienced profilers have proven to produce better profiles than the other respondents. Nevertheless, all groups of respondents managed to produce crime profiles that were beyond a satisfactory level. Therefore, it was concluded from the study that educational background and profiling training were not significant factors in measuring a person's accuracy nor ability in generating a credible criminal profile (Pinizzotto \& Finkel, 1990).

Richard N. Kocsis concurrently conducted three studies to compare the accuracy of crime profiles produced between professional profilers, psychologists, self-identified psychics, college students and several groups of law enforcement officers. In each of the studies, every respondent will review the crime descriptions and actual case materials as well as completing a number of multiplechoice questions regarding the case suspects. The findings of the study found that the crime profiles produced by professional profilers had a large number of correct predictions about the perpetrators, which were about $45 \%$ to $70 \%$ accurate.

Still, Kocsis also found that there were significant differences regarding the criminal profiles produced by the professional profilers themselves. Thus, he argued that experience was not a key requirement to measure the accuracy of a criminal profile because the differentiating factors failed to be identified whether due to profiling aspects or other particular aspects of a case. It was also distinctively proposed for more researches in regards to this area to be conducted to gain a clearer view (Richard N. Kocsis, 2003).

According to Chifflet in an article, "Questioning the validity of criminal profiling: An evidencebased approach", the actual validity and accuracy of criminal profiling had yet to be dissected on and it was difficult to find a good yardstick to attest to it. In ensuring that a criminal profile was credible, measuring its accuracy alone would not be enough as there were various aspects to be assessed and emphasized beforehand. Other factors such as profiling skills and experience also needed to be considered to avoid uncertainty about criminal profiling being a disciple that could be used safely (Chifflet, 2015).

The article, "Profiling Ethical Issues", published on the World of Forensic Science website have discussed on the implications upon a case when an incompetent or unsuitable person practiced criminal profiling. There would be serious harms caused as well as delays in resolving a case through the proposal of inappropriate investigative directions. The authorities at the same time would have 
risked arresting innocent parties due to being given a criminal profile that was very different from the actual suspect, subsequently leading to a more serious case of wrongful detention and worse the risk of wrongful convictions (Encyclopedia.com., 2019).

It was beyond doubt that several pilot studies have been successful in proving that experience was not an important factor in constructing a credible criminal profile. However, having experience was still very helpful in making a criminal profile acceptable as evidence in the courts. With a specialized knowledge, a profiler would be able to provide a comprehensive description of how one's criminal profile have been generated. It would be in fact, seen as irresponsible and unprofessional of any profilers if they were unable to present the criminal profile using relevant scientific terms, definitions and methods which were the combination of scientific knowledge used in forming such profile.

Thus, and so, to appraise the level of competence of a profiler, their skills, knowledge and abilities would be the collateral evidence in order to identify the programs, training and experience needed to further develop existing skills as well as capabilities. According to Dr. John Thornton, while experience may be a valuable asset, it should not be used as a figurative mask to avoid the essential scientific examination upon all scientifically-shaped evidence. With experience, experts ought to be held more accountable instead to clarify their opinions using justifiable scientific facts (Thornton, J.I., 1997).

\section{The Challenges of Practicing Criminal Profiling in Malaysia}

Around the year 2013, the criminal profiling approach started making its mark and have grasped the attention of both the media and non-governmental organizations in Malaysia when the then Secretary General of the Ministry of Home Affairs, Datuk Seri Abdul Rahim Mohamad Radzi revealed that at 28.926 individuals, the majority of gang members or thugs were Indians, followed by the Chinese at 8,214 and Malays, 1923. The classification of criminal activities based on races raised the concerns among some parties as highlighted by the Secretary of MIC Youth, C. Sivarrajh whom have stated that depicting Indians as the majority of gang members would only serve to exacerbate the gang problems in Malaysia. At the same time, it also gave a bad perception of the race itself as if there were plentiful of Indian thugs roaming around (Anon, 2013). The same issue once again reached the media's attention in 2016, via a statement made by Jerald Joseph, the director of a popular human rights communications centre, Pusat KOMAS. According to him, the "trend" of racial crimes showed an increase of the racial discrimination in Malaysia (Ram Anand, 2016; AlShaer.H, et.Al, 2021).

The criminal profiling approach based on race and ethnicity (racial profiling) which have been increasingly and clearly used by the authorities can create tension in the society itself. The unity between our multi-racial people would be jeopardized and spiraled towards violation of the right to equality as enshrined in the Federal Constitution. The contrast in backgrounds and approaches applied by investigating officers when generating criminal profiles would not only implicate that unethical procedures being used and there exist inefficiency of information but also increasing the rate of misconceptions in the future. For this reason, a more in-depth study on the crime profiling method practiced in Malaysia should be implemented and the discussion in regards to it should include theoretical as well as practical aspects which have been rooted from the Malaysian society.

Locally, there was severe lack of writings and even discussions on criminal profiling in the legal aspect. Several studies that could be related to it only explored more on the social, scientific and psychological aspects. It had also been with slight difficulty for the writer to come across studies that discussed on the functions of the criminal profiling itself in the local field. While rather scarce, there were fortunately some who touched on the criminal profiling method in their writings. For example, Siti Nurkhairina (2019) in her article, "Criminal Profile of Women Prisoners in Malaysia: A Qualitative Study", that mentioned on how criminal profiling process was conducted on prisoners after a conviction have been imposed upon them. The method in her study however was merely used towards collecting data and information which centered on four types of criminal offenses as well as 
the factors contributing to those offenses being committed (Siti Nurkhairina, 2019). A similar study was done in 2012 by Dr. Rachel Samuel a/p Samuel, Dr. Roaimah binti Omar and Dr. Rohana Ariffin entitled "Socio-Demographic Characteristics of Female Criminals at The Kajang Women Prison, Malaysia." (Rachel Samuel \& et al., 2012) Both the studies focused on female prisoners as they found that studies on female prisoners committing heinous crimes were fewer in the field than that of male prisoners.

Regardless, several efforts that can contribute to the development of crime profiling methods in Malaysia have already been implemented. Among them was the development of the Penang State Crime Mapping Application (Polgis-Pen) 2012 (Police Online Geographical Information System for Penang). The app was developed to record the details and locations of crimes for when a police report was made and to analyze crimes as well as information on eSector. Not only that, it also facilitated in devising crime statistics in Penang. The categories of crimes put on alert by the app were Violent Crimes and Property Crimes. Through the app, data based on geographical approach have contributed in assisting and speeding up the process of crime profiling (Simposium Maklumat Geospatial Kebangsaan (NGIS) ke 5, 2012).

According to an article entitled, "Criminal Profiling", published by the Skeptic Magazine in 2008, other than countries such as Sweden, Russia and Canada, Malaysia also used criminal profiling as one of the important methods in investigations (Snook, B. \& et al., 2008). The practice of this method can be identified in Part V, Chapter 13 of the Criminal Procedure Code (referred to as "the Code" from this point onwards) starting from section 107 up to 120 in regards to information to the police and their power to investigate. The relation to criminal profiling was also indicated in Part VIII, Chapter 33, Section 329 of the same Code that provided on the duty of police to investigate deaths. However, for the purpose of this study, only Part V, Chapter 13 would be focused on.

The investigation procedure provided in Chapter 13 of the Code has been viewed as too general and chaste, also concerning more on physical evidence whereas evidence from the psychological point of view must also be taken into account at the same time. Scouring through this chapter in its entirety, the author observed that the crime profiling method in Malaysia made use of the investigation analysis and evidence from the incident be it in the form of witnesses, crime scene or criminal remnants. Nevertheless, the author also opined that provisions on the power and procedures of investigation in the Code did not succeed at explaining in detail and with certainty about the criminal profiling method used in investigations by the local police officers.

It was not ruled out by the author somehow that the police was entitled to use any approach deemed appropriate in constructing a criminal profile. Though, it would be unfitting if analyzing the offender's behavior was nowhere applied in said approach considering initial literatures on criminal profiling have stated that the basis of knowledge to construct a criminal profile was through the analysis of the offender's behaviors and psychology. Indisputably, the issue on the broad approaches in criminal profiling method had in a way contributed to the level of admissibility and practicality of such profiles during both the investigation and prosecution process. Such issues were also discussed and covered by literature reviews as well as field studies in foreign countries such as the United States and the United Kingdom.

Additionally, fixed procedures and initial steps ought to be considered in order to diminish the likelihood of discrimination or the surmise of personal opinions without any factual or scientific basis. A uniform procedure can also avoid the issue of lack of preparations and skills being raised in courts up to the point of damaging the reputation of the expert themselves. To come out with flaws or laxity in documentation or other matters involving credibility of statements made in court would also have the potential to compromise the process of justice.

This was displayed in the case of Jayaraman and Ors v Public Prosecutor [1982] 2 MLJ 306 where the Sessions Court judge was not satisfied with the evidence by the doctor called in as a witness to give evidence relating to the type of weapon used in the case. This had been on the ground that the doctor's testimony was given without being guided by any clinical notes as should have been brought along usually when one was called to testify. 
Further on, the sections 108(3) and 109 also provided that only officers or chiefs of the police stations ranking Sergeant and above were eligible to conduct investigations in any seizable case and their actions cannot be questioned at any stages throughout the investigation period. These provisions were regarded as insufficient to provide assurance regarding the credibility of a police officer conducting investigation for seizable offences; that they are indeed qualified and knowledgeable to do so. Other than that, the requirements on qualifications of investigating officers at the same time were seemingly too broad and lax.

As stated on the Official Portal of the Royal Malaysia Police website, the minimum requirement for a person to be a police officer with the rank of Sergeant was to have at least a diploma in any field required and recognized by the Government. And this have been viewed as not helping with building the confidence in their ability to investigate seizable cases which were usually considered to be heavyweights. Those type of cases in fact required for an experienced officer and a higher standard of skills than those of a regular police officer's.

The case of Mohd Zuki b Ali@ Mohamad v PP [2010] MLJU 1320 was one of the cases that highlighted how the incompetence of the police while conducting investigations led to the Court setting aside both the conviction as well as sentence of the appellant. That had happened because of the police's failure to uncover the truth and the fact that they also have collected evidence as well statements solely for the purpose to begin the prosecution. The investigation for the case was not conducted thoroughly and only displayed evidence in favor of the appellant's conviction when in fact, the police were responsible to submit all relevant evidence even though when there was a possibility that the evidence can release the appellant from conviction.

Another case which has seen the Court setting aside convictions and sentences by trial judges due to the police's negligence during the investigation process would be the case of Ihsan $b$ Abdullah v Public Prosecutor [2010] MLJU 60o. The appellant was acquitted due to the failure of the investigating officer to submit any supporting evidence. There have been no submission of the investigation diary to the court to show that the alleged investigation efforts was carried out. There were no recordings of conversations from the interviewed witnesses. To add to it, no comprehensive effort has been made by the police to ensure that the two key witnesses in the case were present at the court such as imposing bonds upon them.

From the result of an interview with an investigating officer working at the Kinabatangan District Police Station, the author discovered that education may apparently not be the main factor for a person to qualify and be appointed as an investigating officer at a police station. Despite that those who have been offered a promotion as an investigating officer would need to undergo some courses conducted by the Malaysian Police Training Centre (PULAPOL) first thing first, these courses are deemed as insufficient as the author have observed at firsthand how the officer interviewed was not successful in explaining the method of crime profiling from a scientific point of view. The explanation given for each stages of an investigation in fact was more inclined towards his experiences alone instead.

Be that as it may, there was a record of a murder case with unknown perpetrator that had eventually been successful in prosecuting someone using criminal profiling methods; Izwanuddin Kasim v Public Prosecutor [2020] 1 LNS 1568. The prosecution case took place after the accused's criminal profile was successfully generated by two investigating officers ranking ASP and DSP respectively through investigation by way of analyzing information from the crime scene, witness statements, police reports and also forensic reports.

It was again reiterated that experience was very helpful in making a crime profile credible as an evidence in the court. Still and all, with specialized knowledge, a profiler would be able to lay out a comprehensive elucidation of how the crime profile have been generated using a combination of few scientific knowledge. It would be unprofessional and reckless of the profilers if they were not able to explain the crime profile using relevant scientific terms, definitions and methods.

Conspicuously, there was a dire need for the qualifications of police officers as stipulated in the section discussed to be refined exhaustively as the credibility of investigating police officers would 
affect the validity of investigative reports prepared and ergo, exposing them to the risk of being disputed or put on doubt. Such improvement can be done either by adding additional provisions which detailed on their qualifications much further or creating a special guideline entirely that would be read together alongside the section itself. It was important to ensure that the investigating officers involved have the appropriate education as well as experience to ensure that the process and investigation papers produced are unquestionable and can be used as evidence in court.

To such degree, the differences in background as well as approaches used by investigating officers when conducting a criminal profile can contribute to the generated crime profile being unreliable and in turn had the potential for wrongful arrests being made. On this account, the author restated for there to be a more in-depth study on the method of crime profiling in Malaysia and for the discussions circulating it to include the theoretical as well as practical aspects within the framework of our local society.

\section{Conclusion}

In respect of the discussion on some of the significant researches compiled in this writing, evidently progression for researchers and law enforcement in designing and creating a uniform and conclusive system was feasible. The definition of criminal profile was already made clear at this point. The author concurred with the definition by Richard N. Kocsis because it was more comprehensive and open, also did not create restrictions for researchers and crime profilers to use any field of knowledge and methodology in the profiling process. It was impossible to obtain an accurate and definitive profile if the scope of knowledge and methodology used as references was limited. After all, what more important has been the goal of the profiling method itself which was to design a profile that can further narrowed down the scope of the investigations conducted and sped up the process for the authorities.

Moving onwards to the methodology aspect, the author agreed with the opinion of Charles Frost in using the "Investigative Process Management" during investigations conducted. This methodology took into account various aspects, fields of knowledge and also the experiences of a profiler when constructing the system of said management. Frost did not reject any of the methodologies already developed by researchers or enforcers. Instead, he was of the opinion that whichever the methodologies that have proven its efficiency in generating highly accurate and valid crime profiles ought to be recorded, compiled and processed into an integrated system which then could be used as a guideline for crime profilers around the globe (Grover Maurice Godwin. ed., tt).

Next, regarding the background of criminal profiling, the author been of the same mind with Chifflet in his article, "Questioning the validity of criminal profiling: An evidence-based approach", that the experience on investigations and the training of profilers on criminal profiling methods were both crucial factors to be considered when recognizing a profile that have been generated. Consequently, the author rejected the opinion of Kocsis who stated that experience was not a major factor that qualified a person to be a crime profiler. Again, the main goal of the criminal profile was to narrow the scope of the offender so the experience of the profiler was important in order to reduce any errors or inaccuracy that might be present in the profiles. Having experience would also in a way provide exposure from a practical point of view and help said profiler to evaluate a case more thoroughly and conclusively.

Notwithstanding the articles and guidelines which covered on criminal profiling that have been discussed, there were still very little of similar discussions in Malaysia and most were not even specific on the procedures and practices of criminal profiling during criminal investigations. Among the challenges that have yet to be conquered would be the uniformity in terms of definition, methodology and also the qualifications of profiling officers. All these lead to the struggle for criminal profile to be accepted as a credible expert evidence in courts due to its accuracy and validity being questionable, a result of the absence of a single yardstick to determine the credibility of a crime profiler. From what being displayed by discussions overseas, more researches should be conducted as 
similar issues too have been clearly visible in a well-established, systematic and internationallyrecognized criminal profile system such as that in the United States.

On a final note, the author proposed for the literature reviews on crime profiling in the context of Malaysian law to be multiplied in their numbers so that the practice of criminal profiling in Malaysia could be refined appropriately to the context of our law and society. In addition, it was also suggested for a special guideline to be created in order to improve the quality of not only the profiling officers but also the crime profiling methods in Malaysia by taking into account the legislations and modules used by foreign countries such as the United States and the United Kingdom.

\section{Acknowledgement}

The authors wish to thank the Ministry of Higher Education (Malaysia) for providing the research grant funding under Fundamental Research Grant Scheme (FRGS), FRGS/1/2020/SSIo/UKM/o2/19

\section{References}

Alison, L, Smith, M., \& Morgan, K. (2003). Interpreting the accuracy of offender profiles. Psychology, Crime, \& Law, 9(2), p. 185-195.

Asha Bolton. (2019). Media Effects and Criminal Profiling: How Fiction Influences Perception and Profile Accuracy, Ph.D thesis, Nova Southeastern University,. p 2.

Anon. (2013). 'Indians in gangs: Some see profiling, others say reality,' o2 Sep 2013. https://www.malaymail.com /news/malaysia/2013/o9/o2/indians-in-gangs-some-see-profiling-others-say-reality/518483 (20 Oktober 2020)

Bosco, D., Zappala', A., \& Santtila, P.' (2010). The admissibility of offender profiling in courtroom: A review of legal issues and court opinions.", International Journal of Law and Psychiatry, 33, p. 184-191.

Brent E. T., et al., (2012) "Criminal Profiling: An Introduction to Behavioral Evidence Analysis", Elsevier Ltd., www.elsevierdirect.com (28 Februari 2021)

Chifflet. (2015). Questioning the validity of criminal profiling: An evidence-based approach, Australian E New Zealand Journal of Criminology, 48, p 238-255.

Criminal Procedure Code

Douglas, J. E., \& Burgess, A. E. (1986). Criminal profiling: A viable investigative tool against violent crime. FBI Law Enforcement Bulletin, 55, p. 9-13.

Alshaer, H., Md. Said, M.H. and Rajamanickam, R. (2021), "The role of the Palestine monetary authority in combating money laundering", Journal of Money Laundering Control, Vol. 24 No. 4, pp. 762-774. https://doi.org/10.1108/JMLC-09-2020-0106

Rachel Samuel a/p Samuel. Roaimah binti Omar. \& Rohana Ariffin. (2012) "Socio-Demographic Characteristics of Female Criminals at The Kajang Women Prison, Malaysia."Research Report, , p 3. http://ir.uitm.edu.my /id/eprint/26410

Encyclopedia.com. (2019). "Profiling, Ethical Issues". World of Forensic Science.

European Union of Fundamental Right Agency. (2018) "Preventing unlawful profiling today and in the future: a guide", Publications Office of the European Union, Luxembourg.

Fox, B., \& Farrington, D. P. (2018) What have we learned from offender profiling? A systematic review and metaanalysis of 40 years of research. Psychological Bulletin, 144(12), p 1247-1274. https://www.researchgate.net/publication/329341074_What_have_we_learned_from_offender_profiling_A_ systematic_review_and_meta-analysis_of_40_years_of_research (20 Oktober 2020).

Grover Maurice Godwin. ed., (tt). Criminal Psychology and Forensic Technology: A Collaborative Approach to Effective Profiling, p 95.

Holmes RM., Holmes ST., (1996) Profiling Violent Crimes: An Investigative Tool. Thousand Oaks; CA, USA: Sage Publications.

Izwanuddin Kasim v. Pendakwa Raya (2020) 1 LNS 1568

Jayaraman dan yang lain lwn Pendakwa Raya (1982)

Lea Winerman. (2004). Criminal profiling: the reality behind the myth, American Psychology Association, Volume 35, No. 7, p. 66. http://www.apa.org/monitor/julaugo4/criminal.aspx

Lauren M. Barrow. ed. et., (2014). "Police and Profiling in the United States: Applying Theory to Criminal Investigations", New York: London, pg3 https://books.google.com.my/books?id=LOzE8YCJspoC\&pg=PR3 \&dq=editions:ISBN1466504366\&source=gbs_selected_pages\&cad=3\#v=onepage\&q\&f=true (28 Februari 2021) 
Marco Strano. (2004). A neural network applied to criminal psychological profiling: An Italian initiative, International Journal of Offender Therapy and Comparative Criminology, 48(4), 495.

Nicolae Titulescu, (2020). Criminal Profiling in Crime Investigation, Constantin NEDELCU, Challenges of the Knowledge Society. Criminal Law, p 156. https://creativecommons.org/licenses/by-sa/3.o/(the "License") (16 Oktober 2020).

Norbert Ebisike. (2007) “The Use of Offender Profiling Evidence in Criminal Cases", Ph. D thesis, University School of Law, San Francisco, California, , p 56.

Peter B. Ainsworth. (2001) Offender Profiling and Crime Analysis, Devon, Willan Publishing, New York, , p 15.

Pinizzotto, A. J., \& Finkel, N. J. (1990). Criminal personality profiling: An outcome and process study. Law and Human Behavior, 14, 215-233.

Richard N. Kocsis. (2006). Criminal Profiling: Principles and Practice, Humana Press Inc., Totowa, New Jersey,. p 2.

Richard N. Kocsis, (2003). Criminal psychological profiling: validities and abilities? Int J Offender Ther Comp Criminal, 47(2), p 126-144.

Sethi, C., \& Barney, K. F. (2017). Serial crime as occupation: Parallels between occupational analysis and psychological profiling. Journal of Occupational Science, 25(2), 283-289. doi: 10.1080/14427591.2017.1366930

Shannon Lynn Vettor. (2011) "Offender Profiling: A Review, Critique, And an Investigation of The Influence of Context, Perception, And Motivations On Sexual Offending”, Ph. D thesis, University of Birmingham, p $13-23$

Simposium Maklumat Geospatial Kebangsaan (NGIS) ke 5, (2012) https://ngis.mygeoportal.gov.my/sites/default /files/Media/ngis5/Kertas\%202-iv\%2oASP\%2oDaniel\%2oKooy\%2o(PDRM\%2oPenang).pdf (18 Januari 2021 ).

Siti Nurkhairina. (Julai 2019). "Profil Jenayah Banduan Wanita di Malaysia: Satu Kajian Kualitatif", Akademika $89(2)$, p $43-56$.

Snook, B., Eastwood, J., Gendreau, P., Goggin, C., \& Cullen, R. M. (2007). Taking stock of criminal profiling: A narrative review and meta-analysis. Criminal Justice and Behavior, 34(4), 437-453.

Stevens, J.A. (1995), Offenders in profile, Policing Today, August, pg 10

Svensson, R., \& Khoshnood, A. (2018). Validity of Criminal Profiling: A Systematic Literature Review. Retrieved from Malmo University Electronic Publishing.

Thornton, J.I. (1997). The General Assumptions and Rationale of Forensic Identification. In:Faigman, D., Kaye, D., Saks, M., et al. (Eds.), Modern Scientific Evidence: The Law and Science of Expert Testimony, vol. 2. West, St. Paul, MN.

Turvey, B. E. (Ed.). (2011). Criminal profiling: An introduction to behavioral evidence analysis.Alaska, AK: Elsevier.

White, J. H., Lester, D., Gentile, M., \& Rosenbleeth, J. (2011). The utilization of forensic science and criminal profiling for capturing serial killers. Forensic Science International, 209(1 3), 160-165.

Winerman, L. (2004). Criminal profiling: The reality behind the myth. Monitor on Psychology, 35(7), 66-69. 